Radical History Review

Issue 131 May 2018

\title{
Hollywood, the Global South, and Total Recall (2012)
}

\author{
Keith B. Wagner
}

$\mathrm{W}$

ritten off as a typical Hollywood science fiction, Len Wiseman's Total

Recall can also be perceived as a spatial analogy for the Global South. In Wiseman's depiction of the Global South, he uses a Hollywoodized megacity, one which is shot almost entirely on studio sets and rendered by computers: a digital city that is a curious amalgamation of real Global South societies and an underdeveloped futurity that should not be ignored. Although I focus entirely on Total Recall, other Hollywood blockbusters such as Cloud Atlas and Babel, as well as certain blockbuster _lms from the Global South such as Metro Manila from the Philippines, Elite Squad: The Enemy Within from Brazil, and District from South Africa, now work within and against visualizing the structural unevenness of power, capital, and people across cities in the world. As a consequence, I view Total Recall as not simply depicting two futuristic megacities - one generic and prosperous in the United Federation of Britain or "UFB," located in the British Isles and Western mainland of Europe, and the other, named the Colony or "New Asia," as more dystopian. Rather, through this urban dichotomy, Total Recall communicates the spatial politics of the South as a cinematic invention itself that has helped to "acquire visibility on the global scene in an assertion of its autonomy, partial autonomy," even if this urban space is imagined.1

In urban studies, Faranak Miraftab and Neema Kudva argue that cities from the Global South can be conceptualized through a range of social forces that they explicate chiefly as the "changing migration patterns and large scale population movements to changes in geopolitical power and the technologies of infrastructure, communication and manufacturing" that all bolster the validity of this concept and illustrate its institutional merit to replace the antecedent term the "Third World" city.2 In applying Miraftab and Kudva's Global South city concept, I believe Total Recall goes some way to imagining the "rising cultural and cinematic importance of emerging cities and the urban regions, which now compete with long established hubs" in the Global North.

To explicate this cinematic imagining happening in both Hollywood and the Global South and to rethink this creative capacity on a global scale, I coin the term Aesthetic Cooperation among Developing and Developed Countries (ACDDC). Briefly put, the ACDDC is a play on the Global South's historical progeny at the Global South Conference on the Technical Cooperation among Developing Countries - known as the TCDC - held in Buenos Aires, Argentina. At this historic meeting, countries adopted the Buenos Aires Plan of Action, which favored a new creative capacity for developing countries to solve their economic and political 
problems through self- reliance and collaborative partnerships with themselves and the North.4 The ACDDC is instructive, I believe, because it stresses an aesthetic hybridity beyond any one style and any one conception of our many North and South urban metropoles found on screen.5

In its narrative construction, Wiseman's millennial reboot represents a substantial departure from Philip K. Dick's original short story, "We Can Remember It for You Wholesale," and Paul Verhoeven's postmodern adaptation entitled Total Recall. Total Recall centers on Earth in the late twenty- first century and not on an off- world colony on Mars; Dick's Mars rebellion was symbolic and conscious of the independence movements in Africa and Asia during the Global Cold War, while Verhoeven's kitschy Mars remained less concerned with addressing this allegory. However, it is not just the old colony powers that Wiseman's is concerned with; rather, he is preoccupied with the Global South as an alternative paradigm that is opposed to neocolonialism and can be understood by way of my ACDDC coinage. In effect, Total Recall depicts a divided anthropocene, longitudinally split between the UFB and the Colony. The residents of the Colony travel to the UFB to work in factories and perform service jobs, traveling in a massive gravity elevator running through the Earth's core colloquially referred to as "China Fall." The image of the Colony from the future Global South is one of the megacity, full of multilingual citizens, polycultural spaces, and amalgamated, rain- soaked architectural forms that range from dilapidated Mexican- style Brutalism to globalized Favelas. In opposition to the Colony, UFB's cinematic representation is articulated as a repressive federation of states, with its capital city London and simulacrum Big Ben and Parliamentary Building put on display and interwoven into a larger set of airy, neoclassical architecture.

The Colony, though, still carrying with it the Third World jingoism of our late twentiethcentury past, is instead depicted in a new register as: an underdeveloped region; an amalgamation of the Global South's futurity; a Hollywoodized Global South megacity that can be thought of in relation to Miraftab and Kudva's apt words on real Global South cities; or, a set of "physical collections of built form specific to a context and global movement, or a mix of cultures over time."6 The Colony's spatial features, with its translocal cultures and "global mélange" of Chinese- KoreanBrazilian- Mexican- Egyptian signage, graf_ti, and languages also provides a realism to its modular habitats.7 This creolization of architectural forms refers back to Hong Kong's cramped and decaying Chungking Mansion, to South Africa's townships and their simple brickwork designs, and to Egypt's crusty but historically integrated Cairo districts; all these signal the further integration and the biunicity of South and North. These new spaces in Total Recall historically reference not only a form of Third Worldism but also send a clear view from the South.

Bursting with revolutionary potential due to its repressed citizens living in dilapidated spaces and dealing with poor working conditions, Total Recall's narrative and spatial interventions come by way of identifying with the Colony's laborers who challenge the automation of jobs and geographical segregation on Wiseman's stratified Earth. The intra- Earth connection via the gravity elevator between North and South provides a further futuristic entanglement "of the South and the North in one another, and the reconfiguration of spatial relationships through the globalization" of location (wealthy megacity versus poor megacity), communication (UFB's control of global media in the South) and labor chains (exploitation of workers from the Colony). 8 In effect, my ACDDC concept presents a Global South topography that recenters the power relations and living spaces, through transnational and subaltern 
resistance and through social and economic misalignment, which are contingent on Global South urbanization (real and cinematic) reimagined by Hollywood.

Keith B. Wagner is assistant professor of Global Media and Culture in the Centre for Multidisciplinary and Intercultural Inquiry at University College London. He is the coeditor of Neoliberalism and Global Cinema: Capital, Culture and Marxist Critique and China's iGeneration:

Cinema and Moving Image Culture for the Twenty First Century. His monographic study entitled Living with Uncertainty: Precarious Work in Global Cinema is under contract with a major US academic press and will be published in 2019.

\section{Notes}

1. Dirlik, "Global South: Predicament and Promise," 15.

2. Miraftab and Kudva, Cities of the Global South Reader, 3.

3. Andersson and Webb, "Introduction: Decentring the Cinematic City," 6.

4. Esteves and Assunção, "South- South cooperation and the international development battlefield."

5. See, for example: Wagner, "Globalizing Discourses"; Traverso, Southern Screens.

6. Miraftab and Kudva, 3.

7. Pieterse, Globalization and Culture.

8. Miraftab and Kudva, 3.

\section{References}

Andersson, Johan, and Lawrence Webb. 2016. "Introduction: Decentring the Cinematic City: Film and Media in the Digital Age." In Global Cinematic Cities: New Landscapes of Film and Media, edited by Andersson and Webb. New York: Columbia University Press.

Dirlik, Arif. 2007. "Global South: Predicament and Promise.” The Global South 1, no. 1.

Esteves, Paulo, and Manaìra Assunção. 2014. "South- South cooperation and the international development battlefield: between the OCED and the UN." Third World Quarterly 35, no. 10.

Miraftab, Faranak, and Neema Kudva, eds. 2015. Cities of the Global South Reader. London: Routledge.

Pieterse, Jan Nederveen. 2009. Globalization and Culture: Global Mélange. Lanham, MD:

Rowman and Littlefield.

Traverso, Antonio, ed. 2017. Southern Screens: Cinema, Culture and the Global South. London: Routledge.

Wagner, Keith B. 2015. "Globalizing Discourses: Literature and Film in the Age of Google." Globalizations 12, no.2. 